\title{
SIMULATIONS AND TESTS OF COMPOSITE MARINE STRUCTURES UNDER LOW-VELOCITY IMPACT
}

\author{
Zhaoyi Zhu \\ Xiaowen $\mathrm{Li}^{*}$ \\ Qinglin Chen \\ Yingqiang Cai \\ Yunfeng Xiong \\ Jimei University, School of Marine Engineering, China \\ Fujian Provincial Key Laboratory for Naval Architecture and Ocean Engineering
}

* Corresponding author: lixw2016@jmu.edu.cn (X.Li)

\begin{abstract}
Due to their excellent performance, composite materials are increasingly used in the marine field. It is ofgreat importance to study the low-velocity impact performance of composite laminates to ensure the operational safety of composite ship structures. Herein, low-velocity drop-weight impact tests were carried out on 12 types of GRP laminates with different layup forms. The impact-induced mechanical response characteristics of the GRP laminates were obtained. Based on the damage model and stiffness degradation criterion of the composite laminates, a low-velocity impact simulation model was proposed by writing a VUMAT subroutine and using the 3D Hashin failure criterion and the cohesive zone model. The fibre failure, matrix failure and interlaminar failure of the composite structures could be determined by this model. The predicted mechanical behaviours of the composite laminates with different layup forms were verified through comparisons with the impact test results, which revealed that the simulation model can well characterise the low-velocity impact process of the composite laminates. According to the damage morphologies of the impact and back sides, the influence of the different layup forms on the low-velocity impact damage of the GRP laminates was summarised. The layup form had great effects on the damage of the composite laminates. Especially, the outer 2-3 layers play a major role in the damage of the impact and the back side. For the same impact energy, the damage areas are larger for the back side than for the impact side, and there is a corresponding layup form to minimise the damage area. Through analyses of the time response relationships of impact force, impactor displacement, rebound velocity and absorbed energy, a better layup form of GRP laminates was obtained. Among the 12 plates, the maximum impact force, absorbed energy and damage area of the plate $P_{4}$ are the smallest, and it has better impact resistance than the others, and can be more in line with the requirements of composite ships. It is beneficial to study the low-velocity impact performance of composite ship structures.
\end{abstract}

Keywords: Low-velocity impact, marine structure, composites, test, finite element analysis

\section{INTRODUCTION}

Composite laminates are being increasingly used in lightweight structural components for a variety of engineering fields, such as the aerospace, automotive, marine and wind turbine sectors, because of their high strength-to-weight and stiffness-to-weight ratios, good fatigue performance and excellent corrosion resistance [1-3]. In the marine engineering field, fibre-reinforced composite materials can be used as hull panels, superstructure, main hull, propellers and fishing tools, etc. [4-5]. However, due to their complicated operating environment, ships are often affected by various low-velocity impacts, such as collisions with other marine structures, floating objects, rocks, docks, and anchors. These low-velocity impacts often lead to internal damage to the composite hull structure, which cannot be observed by the human eye and severely affects the safety of the hull structure.

Based on a literature review, composite structures are more susceptible to impact damage than similar metallic structures. Although the surface of a composite structure may 
not be visibly damaged or may sustain only slight pits after an impact, a large amount of matrix cracking and delamination damage may occur inside the laminates, and even some fibre fractures may occur. Even low-velocity, low-energy impacts can significantly reduce the mechanical properties of composite structures [6]. Moreover, due to the limitations of testing equipment and technology, internal damage can easily go undetected, which greatly reduces the safety of a ship during its service life. Therefore, at the beginning of the structural design of composite ships, it is of strategic importance to clarify the mechanical properties of composite laminates under low-velocity impact and improve the impact resistance of composite ship structures.

There are two main methods for studying the lowvelocity impact of composite structures: mechanical tests and numerical simulations [7-14]. Common impact tests include drop-weight impact tests (ASTM D7136), Izod and Charpy impact tests (ASTM D256) and pendulum impact tests (ASTM D6110), among which the drop-weight impact method is most widely used. Considering that mechanical tests require more human effort and material resources, many researchers have begun to use numerical methods to simulate the low-velocity impact process of composite structures. Gliszczynski [14] dealt with experimental and numerical investigations of the composite plate subjected to low velocity impact. The numerical analyses were performed in the Ansys ${ }^{\circledast}$ environment. The implicit analyses were conducted with and without the implementation of the progressive failure algorithm and the application of the bilinear traction-separation law. High consistency of numerical and experimental results was achieved. The application of Hashin's criterion led to a valid prediction of the fibre failure areas and to overestimation of the matrix failure areas. Moura et al. [1516] used Abaqus to simulate the low-velocity impact process, and the simulated delamination shape and area were in good agreement with their test results. However, their approach regarded the impact process as a quasi-static process and was unable to simulate the damage evolution process. Hou et al. [17] proposed a failure criterion for matrix and fibres to estimate the matrix cracking and fibre fracture of composite laminates under impact by revising the Tsai-Wu criterion. Luo et al. [18] applied an Abaqus subroutine to simulate the impact damage of laminates, and their simulation results were in good agreement with the experimental results. Wen et al. [19] used Ansys for damage analysis of composite materials, and their simulation results were in good agreement with the experimental results. Zhu et al. [20] established a composite damage simulation model through the VUMAT subroutine in Abaqus and found that the simulated damage area was in good agreement with the test results. Qiu et al. [4] investigated the impact responses and impact-induced damage of typical marine laminates by the FE method and found that the impact behaviours obtained in the simplified FE model are effective and can be comparable with experiments with a short computing time. Zhu et al. [21] used Abaqus for low velocity impact damage of composite laminates for ships, the typical failure modes were simulated by employing the 2D Hashin criterion, and material degradation and a damage factor were taken into account in this model. The dynamic response and damage propagation of laminates were studied. The numerical results agree well with the experimental results. In a word, the numerical study of the low-velocity impact behaviour of laminates is more in-depth in the aerospace field, and the research on marine composite structures needs to be further developed.

Most of the research in the literature was based on finite element software and focused on simulating composite damage or improving failure criteria. In other words, different failure criteria were used to simulate the delamination damage, fibre failure and matrix damage of composite laminates to obtain a force-displacement curve to simulate the actual macroscopic state. With the increasing application of composites in the marine field, the low-velocity impact behaviour of composite hull structures has attracted more attention. There are challenges in using composite laminates in marine engineering, i.e., composites frequently suffer from the effects of impaction, including wave impaction, being hit by ships or other objects, missiles or bullets, and other special conditions. It is important to understand the impact behaviour of laminates. Hence, this study selected a composite yacht structure as the research object, and the mechanical behaviour of composite marine laminates under low-velocity impact was studied through mechanical testing and numerical simulation. The effects of 12 different layup forms on the impact resistance of composite laminates were tested and investigated. The results from this work provide a reference for the study of the low-velocity impact performance of composite ships.

\section{EXPERIMENTAL METHOD}

\section{MATERIAL}

The hull plate of a 75-foot glass-reinforced polymer (GRP) yacht was used as the base plate (No. $\left.\mathrm{P}_{1}\right)$, and its layup form was used as the original layup. According to the original layup of $\mathrm{P}_{1}$, an explorative design was carried out. Table 1 lists the specific layup forms. In the table, "A" represents CSM300, which is a chopped strand mat with an areal mass of $300 \mathrm{~g} /$ $\mathrm{m}^{2}$; "B" represents CSM225, which is a chopped strand mat with an areal mass of $225 \mathrm{~g} / \mathrm{m}^{2}$; "C" represents EDJ300, which is a uniaxial cloth with an areal mass of $300 \mathrm{~g} / \mathrm{m}^{2}$; and " $\mathrm{D}$ " stands for EDJ400, which is a uniaxial cloth with an areal mass of $400 \mathrm{~g} / \mathrm{m}^{2}$. The subscripts $0^{\circ}, 90^{\circ},+45^{\circ}$, and $-45^{\circ}$ represent the fibre direction in a single ply, i.e., the angle between the fibre and the long side of the specimen. In order to make the layers design conform to the actual situation of the shipyard, the above four materials were selected. To investigate the influence of different layup forms on the low-velocity impact of the laminates, the layup sequence and angle were designed on the basis of the original layup. The design mainly followed the following principles: 
1) Layup sequence: ensure that the sequence of the outermost layer $\mathrm{N}_{1}$ to the third layer $\mathrm{N}_{3}$ of the original layup remains unchanged and that the total number of chopped strand mats and uniaxial cloths remains unchanged, changing the position of the uniaxial cloths. And from the fourth layer, at least one layer of chopped strand mat should be laid between every two layers of uniaxial cloths.

2) Laying angle: ensure that the sequence and angle of the outermost layer $\mathrm{N}_{1}$ to the third layer $\mathrm{N}_{3}$ of the original layup remain unchanged and that the total number of chopped strand mats and uniaxial cloths remains unchanged, changing the layup angle of the uniaxial cloths.

Eleven different layup forms derived from the original layup are shown in Table 1 . In the table, $\mathrm{N}_{1}$ is the impact surface, $\mathrm{N}_{2}-\mathrm{N}_{12}$ are the internal layers, and $\mathrm{N}_{13}$ is the back surface of the impact laminates.

The GRP laminates in Table 1 were made by the wet layup process. The dimensions of the 12 GRP laminates were 350 $\mathrm{mm} \times 350 \mathrm{~mm}$. After the laminates were cured (Fig. 1), they were cut into rectangular plates with dimensions of $150 \mathrm{~mm}$ $\times 100 \mathrm{~mm}$, as required by the test specification. To ensure the validity of the test results, three standard specimens were made for each layup form.

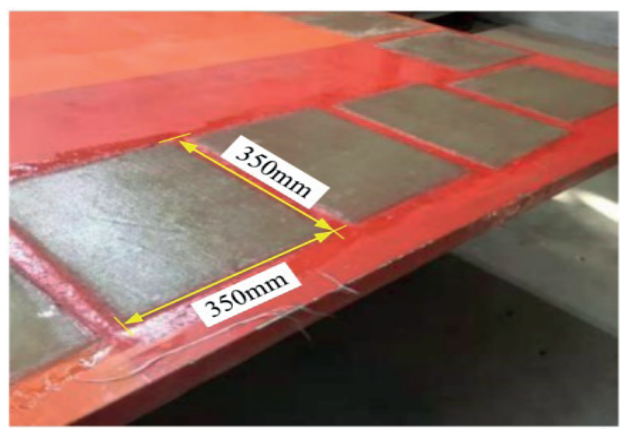

Fig. 1. GRP laminates with different layup forms

Tab. 1. Twelve layup forms used for the GRP laminates

\begin{tabular}{|c|c|c|c|c|c|c|c|c|c|c|c|c|c|}
\hline \multirow{2}{*}{$\begin{array}{c}\text { Plate } \\
\text { number }\end{array}$} & \multicolumn{13}{|c|}{ Layup sequence } \\
\hline & $\mathrm{N}_{1}$ & $\mathrm{~N}_{2}$ & $\mathrm{~N}_{3}$ & $\mathrm{~N}_{4}$ & $\mathrm{~N}_{5}$ & $\mathrm{~N}_{6}$ & $\mathrm{~N}_{7}$ & $\mathrm{~N}_{8}$ & $\mathrm{~N}_{9}$ & $\mathrm{~N}_{10}$ & $\mathrm{~N}_{11}$ & $\mathrm{~N}_{12}$ & $\mathrm{~N}_{13}$ \\
\hline $\mathrm{P}_{1}$ & A & A & B & $\mathrm{C}_{0^{\circ}}$ & $\mathrm{C}_{90^{\circ}}$ & B & $\mathrm{D}_{0^{\circ}}$ & $\mathrm{D}_{90^{\circ}}$ & A & A & B & $\mathrm{C}_{90^{\circ}}$ & $\mathrm{C}_{0^{\circ}}$ \\
\hline $\mathrm{P}_{2}$ & A & A & B & $\mathrm{C}_{0^{\circ}}$ & $\mathrm{C}_{90^{\circ}}$ & B & $\mathrm{C}_{0^{\circ}}$ & $\mathrm{C}_{90^{\circ}}$ & A & A & B & $\mathrm{D}_{90^{\circ}}$ & $\mathrm{D}_{0^{\circ}}$ \\
\hline $\mathrm{P}_{3}$ & A & A & B & $\mathrm{D}_{0^{\circ}}$ & $\mathrm{D}_{90^{\circ}}$ & B & $\mathrm{C}_{0^{\circ}}$ & $\mathrm{C}_{90^{\circ}}$ & A & A & B & $\mathrm{C}_{90^{\circ}}$ & $\mathrm{C}_{0^{\circ}}$ \\
\hline $\mathrm{P}_{4}$ & A & A & B & $\mathrm{C}_{0^{\circ}}$ & $\mathrm{C}_{90^{\circ}}$ & B & $\mathrm{D}_{0^{\circ}}$ & $\mathrm{D}_{90^{\circ}}$ & B & $\mathrm{C}_{0^{\circ}}$ & $\mathrm{C}_{90^{\circ}}$ & A & A \\
\hline $\mathrm{P}_{5}$ & A & A & B & $\mathrm{D}_{0^{\circ}}$ & $\mathrm{D}_{90^{\circ}}$ & B & $\mathrm{C}_{0^{\circ}}$ & $\mathrm{C}_{90^{\circ}}$ & B & $\mathrm{C}_{0^{\circ}}$ & $\mathrm{C}_{90^{\circ}}$ & A & A \\
\hline $\mathrm{P}_{6}$ & A & A & B & $\mathrm{C}_{0^{\circ}}$ & $\mathrm{C}_{90^{\circ}}$ & B & $\mathrm{C}_{0^{\circ}}$ & $\mathrm{C}_{90^{\circ}}$ & B & $\mathrm{D}_{0^{\circ}}$ & $\mathrm{D}_{90^{\circ}}$ & A & A \\
\hline $\mathrm{P}_{7}$ & A & A & B & $\mathrm{C}_{+45^{\circ}}$ & $\mathrm{C}_{-45^{\circ}}$ & B & $\mathrm{D}_{0^{\circ}}$ & $\mathrm{D}_{90^{\circ}}$ & A & A & B & $\mathrm{C}_{90^{\circ}}$ & $\mathrm{C}_{0^{\circ}}$ \\
\hline $\mathrm{P}_{8}$ & A & A & B & $\mathrm{C}_{0^{\circ}}$ & $\mathrm{C}_{90^{\circ}}$ & B & $\mathrm{D}_{+45^{\circ}}$ & $\mathrm{D}_{-45^{\circ}}$ & A & A & B & $\mathrm{C}_{90^{\circ}}$ & $\mathrm{C}_{0^{\circ}}$ \\
\hline $\mathrm{P}_{9}$ & A & A & B & $\mathrm{C}_{0^{\circ}}$ & $\mathrm{C}_{90^{\circ}}$ & B & $\mathrm{D}_{0^{\circ}}$ & $\mathrm{D}_{90^{\circ}}$ & A & A & B & $\mathrm{C}_{+45^{\circ}}$ & $\mathrm{C}_{-45^{\circ}}$ \\
\hline$P_{10}$ & A & A & B & $\mathrm{C}_{+45^{\circ}}$ & $\mathrm{C}_{-45^{\circ}}$ & B & $\mathrm{D}_{0^{\circ}}$ & $\mathrm{D}_{90^{\circ}}$ & A & A & B & $\mathrm{C}_{+45^{\circ}}$ & $\mathrm{C}_{-45^{\circ}}$ \\
\hline$P_{11}$ & A & A & B & $\mathrm{C}_{0^{\circ}}$ & $\mathrm{C}_{90^{\circ}}$ & B & $\mathrm{D}_{+45^{\circ}}$ & $\mathrm{D}_{-45}$ & A & A & B & $\mathrm{C}_{+45^{\circ}}$ & $\mathrm{C}_{-45^{\circ}}$ \\
\hline $\mathrm{P}_{12}$ & A & A & B & $\mathrm{C}_{+45^{\circ}}$ & $\mathrm{C}_{-45^{\circ}}$ & B & $\mathrm{D}_{+45^{\circ}}$ & $\mathrm{D}_{-45}$ & A & A & B & $\mathrm{C}_{90^{\circ}}$ & $\mathrm{C}_{0^{\circ}}$ \\
\hline
\end{tabular}

\section{IMPACT TESTS}

Low-velocity impact tests were performed using an instrumented drop-weight testing machine (ZCJ1302-AD) in accordance with ASTM D7136. Low-velocity impact generally requires a speed less than $10 \mathrm{~m} / \mathrm{s}$ [22-23], known as low-energy impact, which does not break through the composite plate but gives a permanent indentation in its surface. The tests were conducted with a drop-weight tower consisting of two rigid steel columns firmly connected to a metal gantry. The centre of the specimens was impacted with a hemispherical impactor. The impactor was connected to a piezoelectric sensor and was used to carry out the impacts and measure the impact force. The impact velocity was measured through a laser sensor, and an anti-rebound system was used to avoid producing multiple impacts on the same specimen. A rigid fixture was used to hold the specimens. The fixture was mounted onto a rigid steel base via four rigid clamps. Four lateral guiding pins were installed on the fixture to correctly position each specimen, and four clamps were used to hold the specimen during impact. Fig. 2 shows details of both the impactor and the fixture used in the tests. The specimens were placed on the steel base with a $125 \mathrm{~mm} \times 75 \mathrm{~mm}$ cut-out. The initial impact conditions are shown in Table 2.

Tab. 2. Initial impact conditions

\begin{tabular}{|c|c|c|c|}
\hline $\begin{array}{c}\text { Impact energy } \\
(\mathrm{J})\end{array}$ & $\begin{array}{c}\text { Impactor mass } \\
(\mathrm{kg})\end{array}$ & $\begin{array}{c}\text { Impactor } \\
\text { diameter }(\mathrm{mm})\end{array}$ & $\begin{array}{c}\text { Impactor } \\
\text { velocity }(\mathrm{m} / \mathrm{s})\end{array}$ \\
\hline 25 & 2 & 12.5 & 4.98 \\
\hline
\end{tabular}

Impact tests were conducted on the 12 different GRP specimens in the same environment. The tests were divided into 12 groups, and each group was used to carry out repeatability tests on 3 specimens with the same layup form. Fig. 3 shows the impact side and the back side of the 12 specimens after low-velocity impact. The number in the lower-left corner of the figure is the specimen group number (corresponding to the plate number in Table 1), and the number in the upper-right corner is the specimen number in each group.
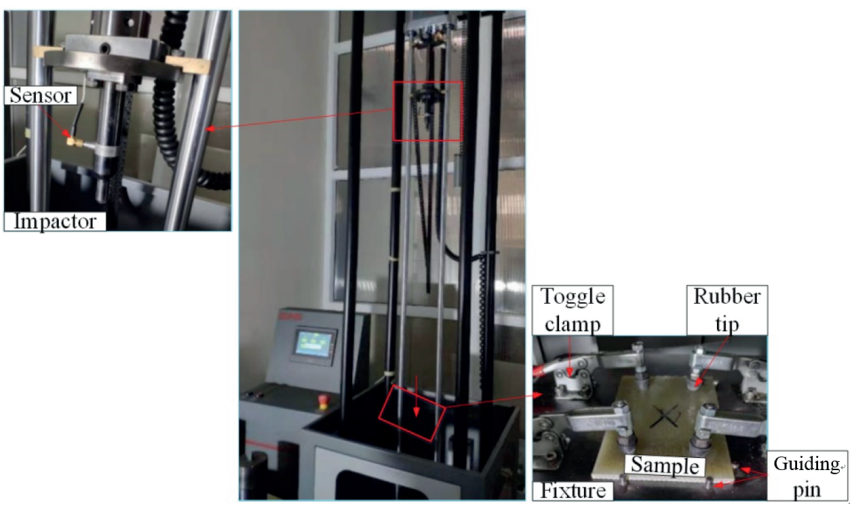

Fig. 2. Drop-weight testing machine 


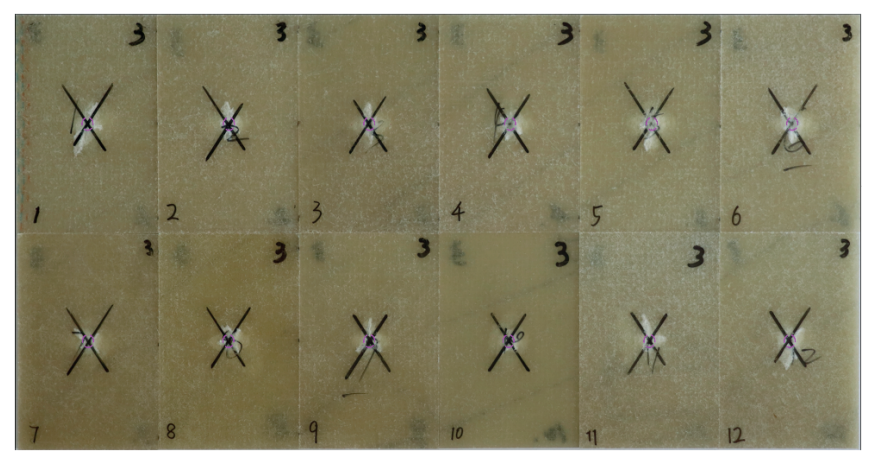

(a) The impact side

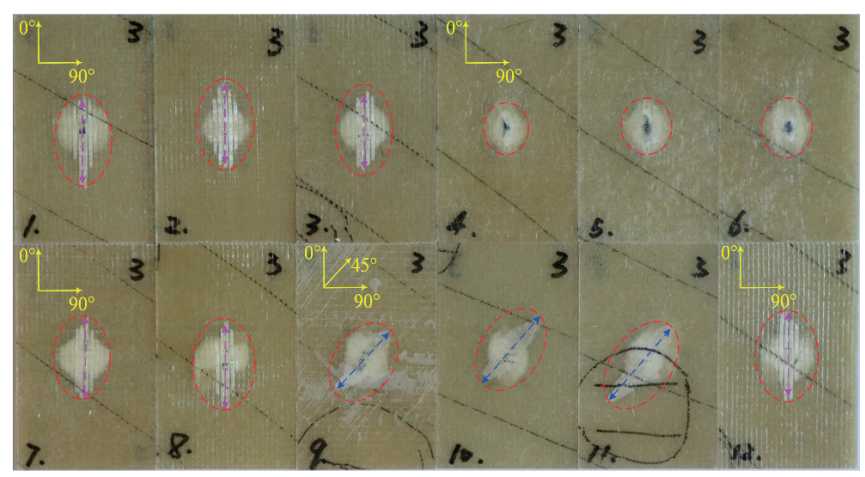

(b) The back side

Fig. 3. The damage morphology of 12 GRP specimens with different layup forms

\section{NUMERICAL ANALYSIS}

The impact behaviour of composite laminates, in which many failure mechanisms occur simultaneously and randomly, is more complex than that of metal materials. In particular, the impact damage of composite structures is a nonlinear problem involving various geometries, materials and contacts. Therefore, in the low-velocity impact simulation process of GRP structures, the damage model of the laminates should be clarified first to obtain effective numerical simulation results.

\section{DAMAGE MODEL}

\section{Intralaminar damage}

(1) Failure criteria

The failure modes of composites mainly include fibre failure, matrix failure and delamination failure. Fibre failure is divided into tensile and compressive fibre failure. Matrix failure is divided into tensile and compressive matrix failure. In the failure process of composite laminates, one failure mode is usually associated with others, or several failure modes occur together. Impact loads further complicate the failure of a composite structure. The literature [24-25] shows that some failure modes of composites have the same characteristics under dynamic and static loads. In other words, the failure mechanism of a composite is not related to the strain rate. Therefore, the failure criterion for quasi-static analysis can be used in dynamic impact analysis. In this paper, the 3D Hashin criterion is used as the failure criterion [26-29]. The corresponding failure mode is as follows:

(1) Tensile fibre failure $\left(\sigma_{11} \geq 0\right)$

$D_{1}=\left(\frac{\sigma_{11}}{\mathrm{X}_{\mathrm{T}}}\right)^{2}+\left(\frac{\tau_{12}}{\mathrm{~S}_{12}}\right)^{2}+\left(\frac{\tau_{13}}{\mathrm{~S}_{13}}\right)^{2}=\left\{\begin{array}{l}\geq 1 \text { failure } \\ <1 \text { no failure }\end{array}\right.$

(2) Compressive fibre failure $\left(\sigma_{11}<0\right)$

$D_{2}=\left(\frac{\sigma_{11}}{\mathrm{X}_{\mathrm{C}}}\right)^{2}=\left\{\begin{array}{l}\geq 1 \text { failure } \\ <1 \text { no failure }\end{array}\right.$

(3) Tensile matrix failure $\left(\sigma_{22}+\sigma_{33} \geq 0\right)$

$D_{3}=\left(\frac{\sigma_{22}+\sigma_{33}}{\mathrm{Y}_{\mathrm{T}}}\right)^{2}+\frac{\tau_{12}^{2}+\tau_{13}^{2}}{\mathrm{~S}_{12}^{2}}+\frac{\tau_{23}^{2}-\sigma_{22} \sigma_{33}}{\mathrm{~S}_{23}^{2}}=\left\{\begin{array}{l}\geq 1 \text { failure } \\ <1 \text { no failure }\end{array}\right.$

(4) Compressive matrix failure $\left(\sigma_{22}+\sigma_{33}<0\right)$

$D_{4}=\frac{\tau_{12}^{2}+\tau_{13}^{2}}{\mathrm{~S}_{12}^{2}}+\frac{\sigma_{22}+\sigma_{33}}{\mathrm{Y}_{\mathrm{C}}}\left[\left(\frac{\mathrm{Y}_{\mathrm{C}}}{2 \mathrm{~S}_{23}}\right)^{2}-1\right]+\frac{\tau_{23}^{2}-\sigma_{22} \sigma_{33}}{\mathrm{~S}_{23}^{2}}+\left(\frac{\sigma_{22}+\sigma_{33}}{2 \mathrm{~S}_{23}}\right)^{2}=\left\{\begin{array}{l}\geq 1 \text { failure } \\ <1 \text { no failure }\end{array}\right.$

In formulas (1)-(4), $D_{1}, D_{2}, D_{3}$, and $D_{4}$ are the damage variables under different failure modes. $\mathrm{X}_{\mathrm{T}}, \mathrm{X}_{\mathrm{C}}, \mathrm{Y}_{\mathrm{T}}$ and $\mathrm{Y}_{\mathrm{C}}$ denote the tensile and compressive strengths of the singlelayer plate in the fibre direction and transverse direction, respectively. $S_{\mathrm{ij}}$ is the shear strength of the single-layer plate corresponding to the $i j$ direction. When the stress state of an element satisfies any of the failure criteria, the corresponding damage mode occurs in this element. When the stress state of an element satisfies more than one of the failure criteria at the same time, a variety of corresponding damage modes occur in this element.

\section{(2) Stiffness degradation model}

The 3D Hashin failure criterion can determine the stressstrain relationship of a composite single-layer plate when the initial damage occurs. After the initial damage, the structure does not immediately lose its bearing capacity. The damage progression in the structure, from the onset of initial damage to the complete collapse of the structure, is a gradual accumulation process, and its essence is that the material stiffness decreases continuously. Thus, the final failure of composite structures cannot be accurately predicted by the Hashin criterion alone. Therefore, the progressive failure analysis method is used [30-31]. After the Hashin criterion determines the initial damage, the material parameters in the damaged area are modified. To realise the effective transition from the undamaged area to the damaged area, the stress in the failure area is reduced according to a certain rule. 
In the calculation process, if the stress state of the element meets the failure criterion, the stiffness degradation of the material is carried out. The elastic parameter of the element is multiplied by some reduction factor. With this material property degradation method, although the element has been damaged, it will continue to contribute to the stiffness of the laminate as long as it exists. In this paper, the Tan stiffness degradation criterion [32-33] is adopted, and the specific stiffness degradation scheme is shown in Table 3.

Tab. 3. Tan stiffness degradation criterion

\begin{tabular}{|l|l|}
\hline Failure mode & Stiffness degradation \\
\hline Tensile fibre failure & $\begin{array}{l}E_{11}^{\prime}=0.07 E_{11}, G_{12}^{\prime}=0.07 G_{12}, G_{13}{ }^{\prime}=0.07 G_{13}, \\
v_{12},=0.07 v_{12}, v_{13}^{\prime}=0.07 v_{13}\end{array}$ \\
\hline Compressive fibre failure & $\begin{array}{l}E_{11}^{\prime}=0.14 E_{11}, G_{12}^{\prime}=0.14 G_{12}, G_{13}{ }^{\prime}=0.14 G_{13}, \\
v_{12}^{\prime}=0.14 v_{12}, v_{13}^{\prime}=0.14 v_{13}\end{array}$ \\
\hline Tensile matrix failure & $\begin{array}{l}E_{22}{ }^{\prime}=0.2 E_{22}, E_{33}^{\prime}=0.2 E_{33}, G_{23}{ }^{\prime}=0.2 G_{23}, \\
v_{12}=0.2 v_{12}, v_{23}^{\prime}=0.2 v_{233}\end{array}$ \\
\hline $\begin{array}{l}\text { Compressive matrix } \\
\text { failure }\end{array}$ & $\begin{array}{l}E_{22}{ }^{\prime}=0.4 E_{22}, E_{33}^{\prime}=0.4 E_{33}, G_{23}{ }^{\prime}=0.4 G_{23}, \\
v_{12}^{\prime}=0.4 v_{12}, v_{23}^{\prime}=0.4 v_{23}\end{array}$ \\
\hline
\end{tabular}

In the VUMAT subroutine of Abaqus, the state variables corresponding to the four failure modes are defined according to the Hashin criterion. The value of the state variable is 0 before the element failure, and is set to 1 when the failure occurs. Then the corresponding parameters are reduced according to Table 3. At the beginning of the incremental step, the state variables of the element (corresponding to various failure modes) are determined first, and the material parameters of this element are obtained (according to the stiffness degradation coefficient in Table 3). Second, the strain increment is applied and the stress is updated. Next, the Hashin criterion is used to determine whether a new failure occurs. If so, the corresponding state variable is set to 1 and the corresponding parameters are reduced. Finally, the stress under this incremental step is recalculated by using the new material parameters, and the incremental step of this element is over. Considering the irreversibility of the damage, once a state variable of the element is set to 1 , the elastic parameters will not change after a reduction. When two or more failure modes occur in the same element, the minimum value of the degradation coefficient corresponding to different failure modes shall be taken. If there is an element with serious shape distortion, it will be deleted.

\section{Interlaminar damage}

The cohesive zone model based on the traction-separation constitutive relation was used to predict the interlaminar damage under low-velocity impact, and the damage constitutive relationship is shown in Fig. 4. The initiation of damage is based on a quadratic traction-separation law [34]; see formula (5). Once failure is initiated, it propagates following the element energy release rate. The mixed-mode damage evolution criterion (B-K criterion) proposed by Benzeggagh and Kenane was adopted to characterise the expansion law of interlaminar damage [35]; see formula (6).

$$
\left(\frac{\left\langle\sigma_{\mathrm{n}}\right\rangle}{N}\right)^{2}+\left(\frac{\sigma_{\mathrm{t}}}{S}\right)^{2}+\left(\frac{\sigma_{\mathrm{s}}}{T}\right)^{2} \geq 1
$$

where $\sigma_{\mathrm{n}}, \sigma_{\mathrm{t}}$ and $\sigma_{\mathrm{s}}$ represent normal traction and shear traction, respectively; $\left\langle\sigma_{n}\right\rangle=\left(\sigma_{n}+\left|\sigma_{n}\right|\right) / 2$; and $\mathrm{N}, \mathrm{S}$ and $\mathrm{T}$ are the normal strength and shear strength of the interface, respectively.

$$
G_{\mathrm{C}}=G_{\mathrm{IC}}+\left(G_{\mathrm{IIC}}-G_{\mathrm{IC}}\right)\left(\frac{G_{\mathrm{IIC}}+G_{\mathrm{IIIC}}}{G_{\mathrm{IC}}+G_{\mathrm{IIC}}+G_{\mathrm{IIIC}}}\right)^{\eta}
$$

where $G_{C}$ is the mixed-mode fracture toughness; $G_{I C}, G_{\text {IIC }}$ and $\mathrm{G}_{\mathrm{IIIC}}$ are the critical energy release rates of type I, type II and type II, respectively; and $\eta$ is the $\mathrm{B}-\mathrm{K}$ power law parameter and is related to the material. For carbon fibre or glass fibre reinforced resin composites, the value of $\eta$ is in the range of 1-2[33,36-38]. Based on previous studies and finite element calculations, $\eta$ is 1.45 in this paper.

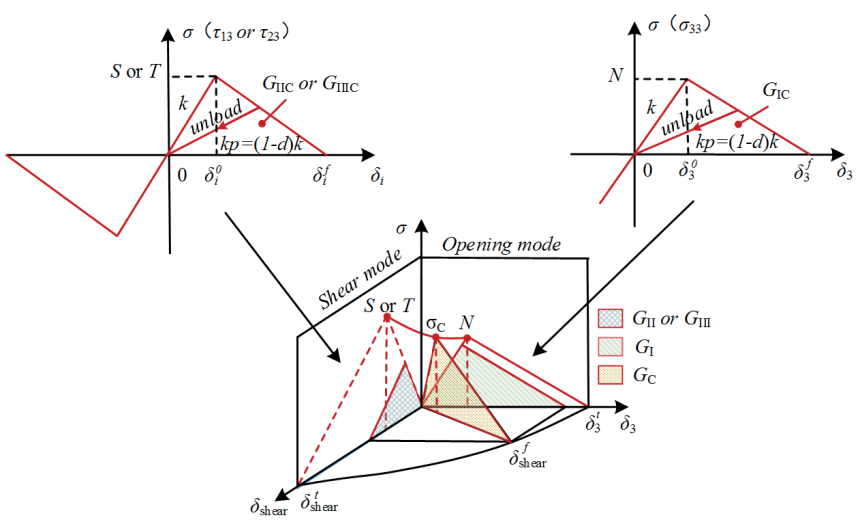

Fig. 4. Damage constitutive relation

\section{MODELLING OF IMPACT ON COMPOSITE LAMINATES}

\section{Finite element model}

According to the specific conditions of the low-velocity impact test, a finite element model was developed in Abaqus/ Implicit, as shown in Fig. 5. The whole model was created in three parts, the impactor, laminate and the base. The hemispherical impactor and the base were simplified as analytical rigid bodies. The single-layer plate was discretised with 8-node reduced-integration solid elements (C3D8R), and the layers were connected by $0.02 \mathrm{~mm} 3 \mathrm{D}$ cohesive elements (COH3D8), which can simulate the mechanical behaviour between layers. The laminate model contains 129,600 solid elements and 124,200 cohesive elements. The dimensions of the laminate were $150 \mathrm{~mm} \times 100 \mathrm{~mm} \times 6.52 \mathrm{~mm}$. 


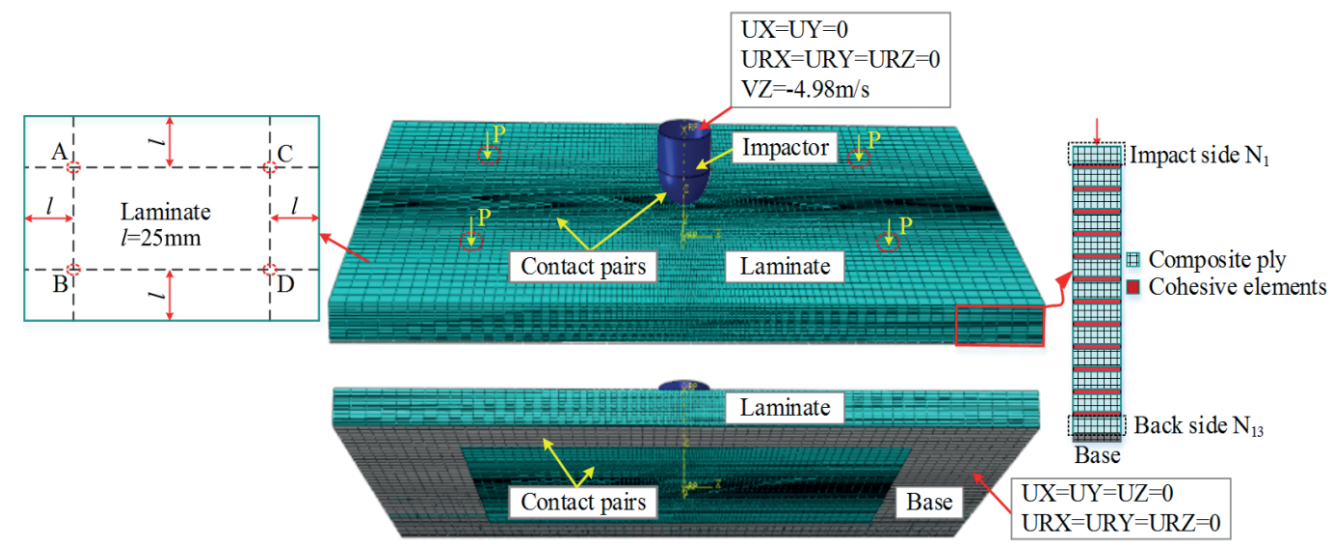

Fig. 5. Finite element model for impact analyses

In the experiment the analysed laminate was supported on the base and was additionally stabilised by four rubber tips of the toggle clamps. In order to simplify the boundary conditions and reflect the real experimental testing as much as possible, the rigid body displacement of the laminate was restricted by the fixture base and the toggle clamps. A standard surface-to-surface contact algorithm available in Abaqus/Implicit was used to simulate the impactor-laminate contact and the laminate-base contact during impact. And at the position of the rubber tips (red dotted line in Fig. 5), the force $\mathrm{P}$ along the $\mathrm{Z}$ axis was applied to simulate the restraint effect of the clamping element. And based on ASTM D7136 standard, the value of $P$ is equal to $-275 \mathrm{~N}$. Compared with the specimen deformation, the deformation of the base during the impact process was negligible, so the base was set as a fixed constraint during the analysis process. The impactor was free in the $\mathrm{Z}$ direction and constrained in the $\mathrm{X}$ and $\mathrm{Y}$ directions.

\section{Material properties}

GRP laminates consist of two main materials, chopped strand mat and axial cloth, and their mechanical properties are shown in Table 4 . In the table, $X_{T}$ and $X_{C}$ are the tensile and compressive strengths in the fibre direction, respectively; $\mathrm{Y}_{\mathrm{T}}$ and $\mathrm{Y}_{\mathrm{C}}$ are the tensile and compressive strengths in the orthogonal direction of the fibre, respectively; $Z_{\mathrm{T}}$ and $Z_{C}$ are the tensile and compressive strengths in the thickness direction of the laminates, respectively; $S_{12}$, $S_{13}, S_{23}$ are the shear strengths in the 12,13 , and 23 directions, respectively; $\rho$ is the material density; and $h$ is the thickness of a single-layer plate. The parameters of the cohesive interface elements are shown in Table 5. In the table, $E$ is the elastic modulus of the interface layer, $G_{1}$ is the shear modulus in the 1 direction, and $G_{2}$ is the shear modulus in the 2 direction.

Table 4. Material properties used in the finite element analyses

\begin{tabular}{|l|c|c|c|c|}
\hline \multirow{2}{*}{ Properties } & \multicolumn{4}{|c|}{ Materials } \\
\cline { 2 - 5 } & A & B & C & D \\
\hline$E_{1}(\mathrm{MPa})$ & 13600 & 11600 & 23500 & 25600 \\
\hline
\end{tabular}

\begin{tabular}{|l|c|c|c|c|}
\hline \multirow{2}{*}{ Properties } & \multicolumn{4}{|c|}{ Materials } \\
\cline { 2 - 5 } & A & B & C & D \\
\hline$E_{2}(\mathrm{MPa})$ & 13600 & 11600 & 6560 & 7120 \\
\hline$E_{3}(\mathrm{MPa})$ & 10700 & 8062 & 6560 & 7120 \\
\hline$v_{12}$ & 0.321 & 0.347 & 0.205 & 0.237 \\
\hline$v_{13}$ & 0.127 & 0.139 & 0.205 & 0.237 \\
\hline$v_{23}$ & 0.105 & 0.108 & 0.310 & 0.332 \\
\hline$G_{12}(\mathrm{MPa})$ & 7760 & 4602 & 2265 & 2473 \\
\hline$G_{13}(\mathrm{MPa})$ & 5200 & 3847 & 2265 & 2473 \\
\hline$G_{23}(\mathrm{MPa})$ & 5200 & 3847 & 1847 & 2011 \\
\hline $\mathrm{X}_{\mathrm{T}}(\mathrm{MPa})$ & 192 & 186 & 810 & 830 \\
\hline $\mathrm{X}_{\mathrm{C}}(\mathrm{MPa})$ & 260 & 250 & 475 & 490 \\
\hline $\mathrm{Y}_{\mathrm{T}}(\mathrm{MPa})$ & 192 & 186 & 58 & 63 \\
\hline $\mathrm{Y}_{\mathrm{C}}(\mathrm{MPa})$ & 260 & 250 & 145 & 160 \\
\hline $\mathrm{Z}_{\mathrm{T}}(\mathrm{MPa})$ & 76 & 70 & 58 & 63 \\
\hline $\mathrm{Z}_{\mathrm{C}}(\mathrm{MPa})$ & 320 & 310 & 145 & 160 \\
\hline$S_{12}(\mathrm{MPa})$ & 103 & 97 & 59 & 65 \\
\hline$S_{13}(\mathrm{MPa})$ & 66 & 60 & 59 & 65 \\
\hline$S_{23}(\mathrm{MPa})$ & 66 & 60 & 50 & 53 \\
\hline$\left.\rho(\mathrm{kg} / \mathrm{cm})^{3}\right)$ & 1500 & 1320 & 1790 & 1800 \\
\hline$h(\mathrm{~mm})$ & 0.34 & 0.375 & 0.5 \\
\hline
\end{tabular}

Tab. 5, Interface properties used in the finite element analyses

\begin{tabular}{|c|c|c|}
\hline Modulus $(\mathrm{MPa})$ & Strength $(\mathrm{MPa})$ & Energy release rate $(\mathrm{N} / \mathrm{mm})$ \\
\hline$E=3000$ & $N=20$ & $G_{\mathrm{IC}}=0.249$ \\
\hline$G_{1}=1154$ & $S=25$ & $G_{\mathrm{IIC}}=0.733$ \\
\hline$G_{2}=1154$ & $T=25$ & $G_{\mathrm{IIIC}}=0.733$ \\
\hline
\end{tabular}

Simulation of the low-velocity impact process of laminates

Low-velocity impact simulations were set up in accordance with the test performed in section 2.2. In Abaqus/Explicit, a VUMAT subroutine was used to define the material properties, damage criteria and damage evolution of the composite laminates. Based on the damage model in Section 3.1, the VUMAT subroutine was written in Fortran (Fig. 6). During calculation, this subroutine was used to assign user-defined material properties to the target model and iterate until the calculation was terminated. The specific analysis process is shown in Fig. 7. In each step, the VUMAT 
subroutine obtains the value of stress and strain and the number of elements in the Abaqus main program, judges the damage state and degradation degree of each element, assesses the stress, strain, and damage factor, and then sends this information back to the Abaqus main program.

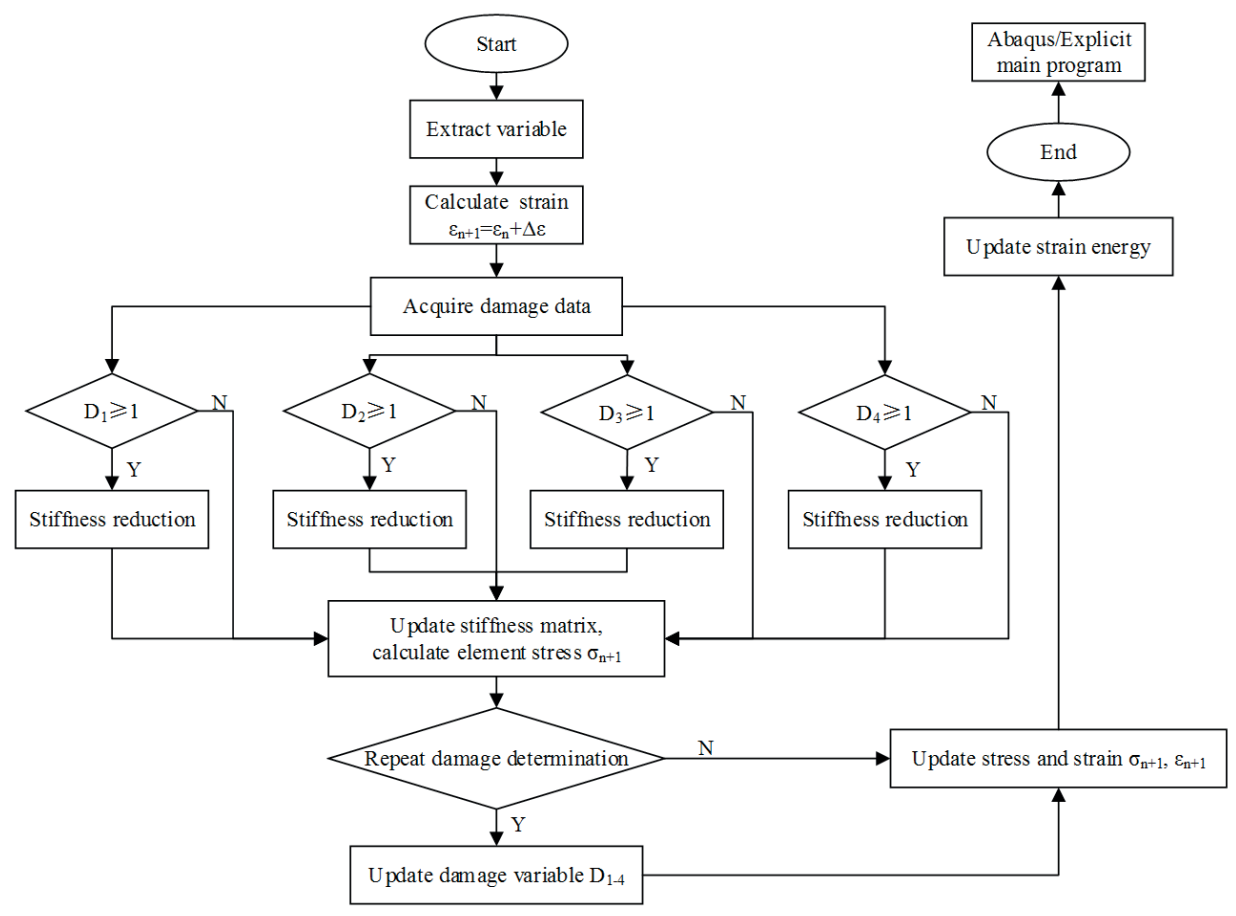

Fig. 6. VUMAT subroutine

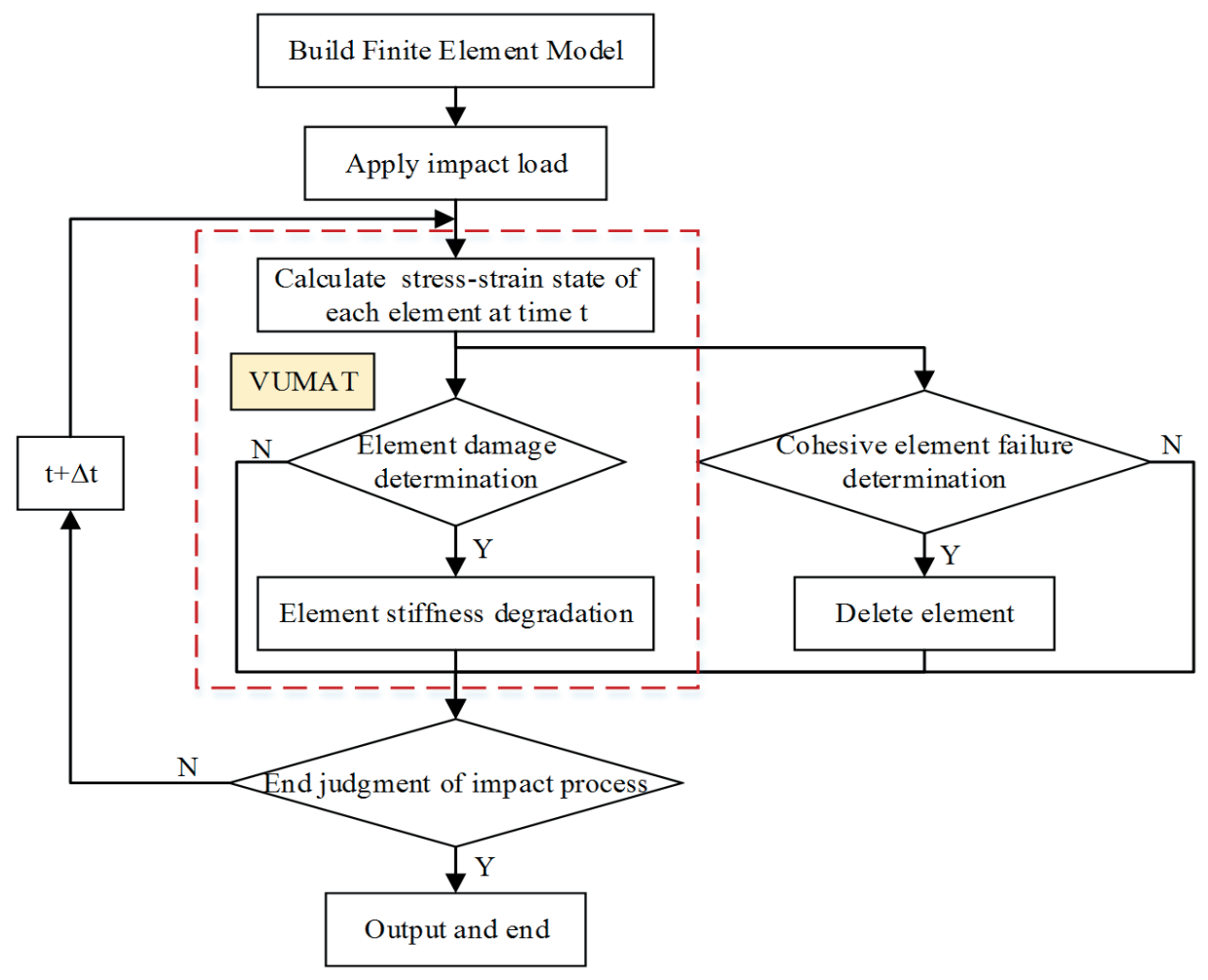

Fig. 7. Numerical analysis flow of the low-velocity impact of laminates

\section{LOW-VELOCITY IMPACT RESULTS}

\section{ANALYSIS OF DAMAGE}

In the same environment, 25J impact tests were carried out on the 12 GRP specimens with different layup forms. Fig. 3 shows the impact and back sides of these specimens after low-velocity impact. The impact load produced varying degrees of fibre, matrix and delamination damage. It should be noted that each plate shown in Fig. 3 is one of three standard specimens and all the experimental values are the average of the three repeated tests. In the preliminary analysis of the results, attention was focused on the areas and the nature of the observed damage [13]. The initial damage occurred at the impact side, and the material at the impact point was plastically deformed. Due to the high contact force, the damage expanded rapidly to the interior of the laminate. As shown in Fig. 3 (a), the damage morphology of the 12 plates is similar. There are obvious pits in the contact position between the impact side and the impactor. These pits are about $9 \mathrm{~mm}$ in diameter. It is well known that the damage is closely related to the layup form. The reason for this phenomenon is that the layup forms of $\mathrm{N}_{1}-\mathrm{N}_{3}$ for all plates are consistent. In order to obtain more damage information, the back side of the tested specimens was analysed. By observing the damage characteristics shown in Fig. 3(b), it was found that the damage morphologies of $\mathrm{P}_{4}-\mathrm{P}_{6}$ were similar, in which fine delamination damage could be seen in a radius of approximately $13 \mathrm{~mm}$ around the centre on the $\mathrm{N}_{13}$ plane. The damage morphologies of $\mathrm{P}_{1}-\mathrm{P}_{3}, \mathrm{P}_{7}, \mathrm{P}_{8}$ and $\mathrm{P}_{12}$ were 
similar, in which fine delamination damage could be seen in an ellipse with a long axis of approximately 58 $\mathrm{mm}$ and a short axis of approximately $40 \mathrm{~mm}$ around the centre, and there was clear fibre delamination damage in the $0^{\circ}$ direction on the $\mathrm{N}_{13}$ plane. The damage morphologies of $\mathrm{P}_{9}-\mathrm{P}_{11}$ were similar, in which fine delamination damage could be seen in an ellipse with a long axis of approximately $60 \mathrm{~mm}$ and a short axis of approximately $30 \mathrm{~mm}$ around the centre and there was obvious fibre delamination damage in the $45^{\circ}$ direction on the $\mathrm{N}_{13}$ plane. Therefore, these 12 plates can be divided into 4 groups, $\mathrm{P}_{1}-\mathrm{P}_{3}, \mathrm{P}_{4}-\mathrm{P}_{6}, \mathrm{P}_{7}$, $\mathrm{P}_{8}, \mathrm{P}_{12}$ and $\mathrm{P}_{9}-\mathrm{P}_{11}$.

Taking the layup form of $\mathrm{P}_{1}$ as a reference, the position and material of the changed layup were marked with symbols. Table 1 was simplified to make the comparative analysis more intuitive, as shown in Table 6 . The analysis shows that the layup form of $\mathrm{P}_{2}$ and $\mathrm{P}_{3}$ is the closest to $\mathrm{P}_{1} ; \mathrm{P}_{4}, \mathrm{P}_{5}$ and $\mathrm{P}_{6}$ have similar layup forms, but $\mathrm{P}_{4}$ has a small difference; the layup forms of $\mathrm{P}_{7}, \mathrm{P}_{8}$, and $\mathrm{P}_{12}$ are similar; $\mathrm{P}_{9}, \mathrm{P}_{10}$ and $\mathrm{P}_{11}$ have similar layup forms. This is consistent with the experimental characterisation results shown in Fig. 3(b).

Tab. 6. The simplified layup forms of GRP laminates

\begin{tabular}{|c|c|c|c|c|c|c|c|c|c|c|c|c|c|}
\hline \multirow{2}{*}{ 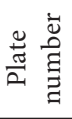 } & \multicolumn{13}{|c|}{ Layup sequence } \\
\hline & $\mathrm{N}_{1}$ & $\mathrm{~N}_{2}$ & $\mathrm{~N}_{3}$ & $\mathrm{~N}_{4}$ & $\mathrm{~N}_{5}$ & $\mathrm{~N}_{6}$ & $\mathrm{~N}_{7}$ & $\mathrm{~N}_{8}$ & $\mathrm{~N}_{9}$ & $\mathrm{~N}_{10}$ & $\mathrm{~N}_{11}$ & $\mathrm{~N}_{12}$ & $\mathrm{~N}_{13}$ \\
\hline \multirow{2}{*}{$\mathrm{P}_{1}$} & A & A & B & $\mathrm{C}_{0^{\circ}}$ & $\mathrm{C}_{90^{\circ}}$ & B & $\mathrm{D}_{0^{\circ}}$ & $\mathrm{D}_{90^{\circ}}$ & A & A & B & $C_{90^{\circ}}$ & $\mathrm{C}_{0^{\circ}}$ \\
\hline & $\cdots$ & $\ldots$ & .. & $\diamond$ & $\square$ & .. & $\diamond$ & $\mathbf{\square}$ & $\cdots$ & $\cdots$ & .. & $\square$ & $\diamond$ \\
\hline $\mathrm{P}_{2}$ & & & & & & & $\diamond$ & $\square$ & & & & $\mathbf{\square}$ & $\diamond$ \\
\hline $\mathrm{P}_{3}$ & & & & $\diamond$ & $\mathbf{\square}$ & & $\diamond$ & $\square$ & & & & & \\
\hline $\mathrm{P}_{4}$ & & & & & & & & & .. & $\diamond$ & $\square$ & $\cdots$ & $\cdots$ \\
\hline $\mathrm{P}_{5}$ & & & & $\diamond$ & - & & $\diamond$ & $\square$ & .. & $\diamond$ & $\square$ & $\cdots$ & $\cdots$ \\
\hline $\mathrm{P}_{6}$ & & & & & & & $\diamond$ & $\square$ & .. & $\diamond$ & $\mathbf{\square}$ & $\cdots$ & $\cdots$ \\
\hline $\mathrm{P}_{7}$ & & & & $\triangle$ & $\nabla$ & & & & & & & & \\
\hline $\mathrm{P}_{8}$ & & & & & & & $\boldsymbol{\Delta}$ & $\nabla$ & & & & & \\
\hline $\mathrm{P}_{9}$ & & & & $\diamond$ & $\square$ & & & & & & & $\triangle$ & $\nabla$ \\
\hline $\mathrm{P}_{10}$ & & & & $\triangle$ & $\nabla$ & & & & & & & $\triangle$ & $\nabla$ \\
\hline $\mathrm{P}_{11}$ & & & & & & & $\boldsymbol{\Delta}$ & $\nabla$ & & & & $\triangle$ & $\nabla$ \\
\hline $\mathrm{P}_{12}$ & & & & $\triangle$ & $\nabla$ & & $\boldsymbol{\Delta}$ & $\nabla$ & & & & & \\
\hline
\end{tabular}

Note: $\triangle, \nabla$ stand for $\mathrm{C}+45^{\circ}, \mathrm{C}-45^{\circ} ; \boldsymbol{\Delta}, \boldsymbol{\nabla}$ stand for $\mathrm{D}-45^{\circ}, \mathrm{D}+45^{\circ}$.

It was discovered that the damage morphology was closely related to the layup form of $\mathrm{N}_{12}$ and $\mathrm{N}_{13}$. $\mathrm{N}_{12}$ and $\mathrm{N}_{13}$ of $\mathrm{P}_{4}-\mathrm{P}_{6}$ were all chopped strand mats, which absorb more energy than uniaxial cloth, and the corresponding damage area was smaller. $\mathrm{N}_{12}$ and $\mathrm{N}_{13}$ of $\mathrm{P}_{1}-\mathrm{P}_{3}, \mathrm{P}_{7}, \mathrm{P}_{8}$ and $\mathrm{P}_{12}$ were uniaxial fabrics laid at $90^{\circ}$ and $0^{\circ}$, respectively; these plates exhibited obvious fibre delamination damage in the $0^{\circ}$ direction. $\mathrm{N}_{12}$ and $\mathrm{N}_{13}$ of $\mathrm{P}_{2}$ were uniaxial cloths with an areal mass of $400 \mathrm{~g} / \mathrm{m}^{2}$, whose strength was slightly higher than those of the $300 \mathrm{~g} / \mathrm{m}^{2}$ uniaxial cloth used in other laminates; accordingly, the damage area of $\mathrm{P}_{2}$ was slightly smaller.
$\mathrm{N}_{12}$ and $\mathrm{N}_{13}$ of $\mathrm{P}_{9}-\mathrm{P}_{11}$ were uniaxial cloths laid at $\pm 45^{\circ}$. There was fibre delamination damage in the $\pm 45^{\circ}$ direction, and the damage area was also slightly larger in these laminates. It is commonly known that the damage area is one of the important characteristics to judge the low-velocity impact damage of laminates. The included damage areas were divided into two parts: blue line outside - maximum damage area, yellow line inside - concentrated damage area, as shown in Fig. 8. With respect to the damage area, Fig. 8 shows the maximum damage area (MDA) and concentrated damage area (MDC) of the 12 tested specimens. The damage areas of each layer partially overlap and the MDC represents the overlapping region of the damage area. $\mathrm{P}_{4}$ has the smallest maximum damage area and concentrated damage area. For the maximum damage scale indicated in Fig. 9, there is $\mathrm{P}_{4}<\mathrm{P}_{5}<\mathrm{P}_{6}<\mathrm{P}_{3}<\mathrm{P}_{7}$ $<\mathrm{P}_{2}<\mathrm{P}_{9}<\mathrm{P}_{10}<\mathrm{P}_{8}<\mathrm{P}_{12}<\mathrm{P}_{1}<\mathrm{P}_{11}$. Among the 12 layup forms, the tested specimens in which $\mathrm{N}_{12}$ and $\mathrm{N}_{13}$ were chopped strand mat had better impact resistance than the specimens where these layers were uniaxial cloths laid at $0^{\circ}$ and $90^{\circ}$ and slightly better than the specimens where these layers were uniaxial cloths laid at $\pm 45^{\circ}$. Analysing the obtained results, it is easy to see that $\mathrm{P}_{4}$ has a better layup form than the others.

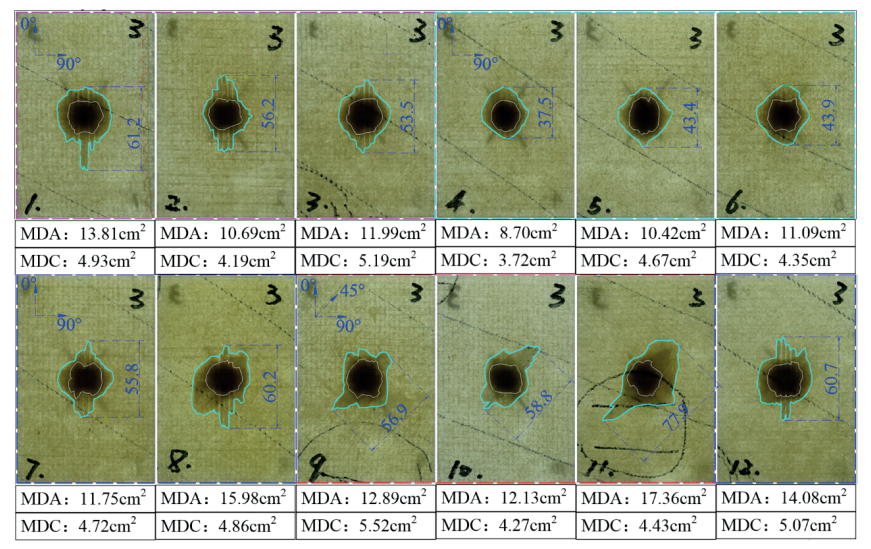

Fig. 8. The damage projection and areas of 12 tested specimens

\section{ANALYSIS OF MECHANICAL RESPONSE}

Fig. 9 shows the simulation process of $\mathrm{P}_{1}$ under impact. Fig. 9(a) shows the state at the beginning of the impact, Fig. 9(b) shows the state at an impact time of $2.5 \mathrm{~ms}$, and Fig. 9(c) shows the state after the impact. Based on $\mathrm{P}_{1}$, the validity of the numerical simulation was verified. According to the results of the tests and simulations, the time response characteristics were analysed in terms of impact force, impactor displacement, impactor speed and absorbed energy. The mechanical behaviour of the GRP laminates under lowvelocity impact was predicted. 


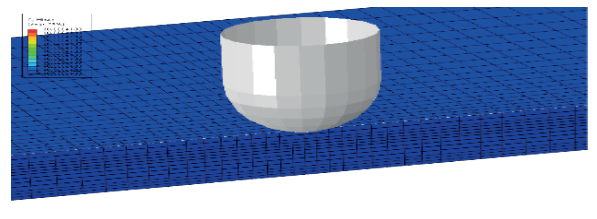

(a) Time $=0 \mathrm{~ms}$

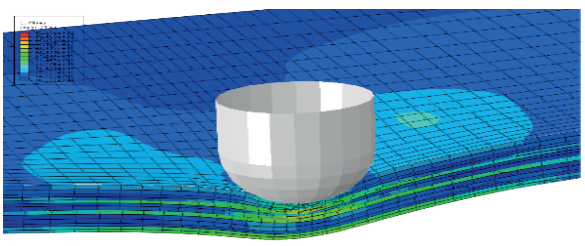

(b) Time $=2.5 \mathrm{~ms}$

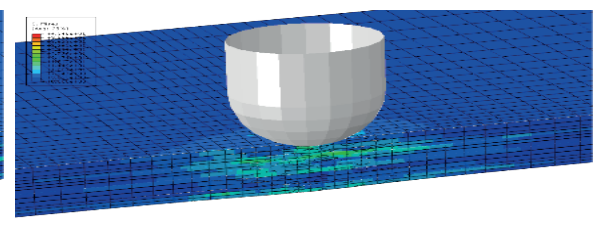

(c) Time $=5 \mathrm{~ms}$
Fig. 9. Simulation process of $P_{1}$ under impact

\section{Impact force-time response}

The force-time histories of $\mathrm{P}_{1}$ are represented in Fig. 10, in which the impact force and the time are represented by $F$ and $t$, respectively. In the elastic phase, the force linearly increased to the initial damage threshold $\left(\mathrm{F}_{\mathrm{H}}\right)$, at which time the initial damage caused the stiffness of the laminate to start to change. Between the initial damage threshold and the peak force, the curves fluctuated mainly due to the damage evolution within and between layers. After the impact force reached the peak $\left(\mathrm{F}_{\mathrm{M}}\right)$, the impactor began to rebound until it separated from the laminates, and the impact force dropped to zero. A comparison shows that the trends from the test and simulation (FE) results of $\mathrm{P}_{1}$ were relatively consistent. The simulation errors of the initial damage threshold and the peak force were $8.7 \%$ and $4.1 \%$, respectively.

Fig. 10 shows that the simulation curve fluctuated slightly more than the test curve. One reason for this discrepancy is that the Tan stiffness degradation criterion was adopted in the simulation. After the elements reached the damage criterion, the stiffness suddenly decreased, which can cause a sudden change in the stiffness of the entire laminate and result in an unstable contact force. Another potential reason for this discrepancy is that the grid accuracy was not sufficient, and the stiffness degradation of a single element had a significant effect on the stiffness of the entire laminate. The fluctuations in the test curve were relatively gentle because the fibres in the laminates were sufficiently dense. From a macro perspective, damage to the fibres and the matrix occurred gradually. The rigidity of the laminates gradually decreased, so the fluctuations of the impact load were not very violent. After the impactor started to rebound, the impact force-time curves were relatively flat in both the test and the simulation. This was because the laminates were no longer damaged during the rebound process.

The test and simulation results of the maximum impact force of $\mathrm{P}_{1}-\mathrm{P}_{12}$ are shown in Fig. 11. In the test data, the maximum impact force of $\mathrm{P}_{4}-\mathrm{P}_{6}$ was relatively low. A possible reason for this was that $\mathrm{N}_{12}$ and $\mathrm{N}_{13}$ were chopped strand mats with low stiffness, and a uniaxial cloth with greater stiffness was set in the middle of the laminate. Therefore, the stiffness of the entire laminate was relatively low, and the maximum impact force was lower. The maximum impact forces of $\mathrm{P}_{1}-\mathrm{P}_{3}$ and $\mathrm{P}_{7}-\mathrm{P}_{12}$ were relatively high. A possible reason for this was that $N_{12}$ and $N_{13}$ were uniaxial cloths, the stiffness of the whole laminate was relatively high, and the maximum impact force increased accordingly. With different layup forms, the simulation results were consistent with the experimental results. In terms of impact force alone, $\mathrm{P}_{4}$ can effectively disperse the external force concentration, and its layup form is relatively good.

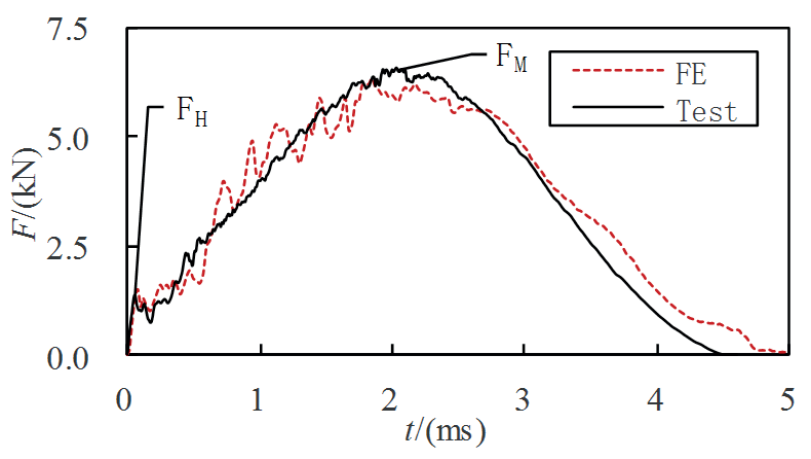

Fig. 10. Force-time histories of $P_{1}$

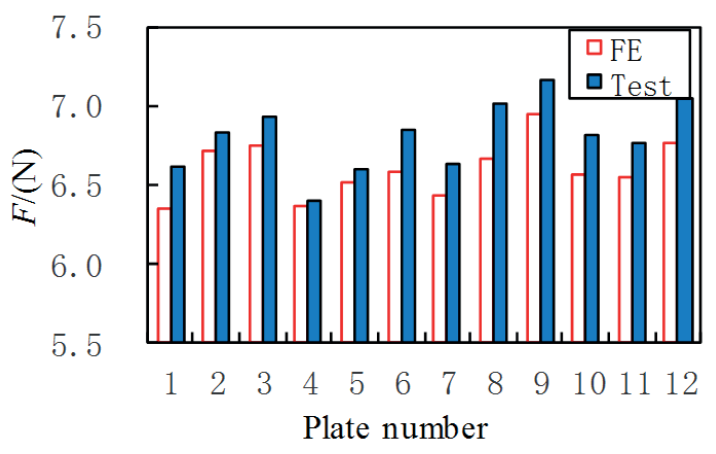

Fig. 11. Maximum impact force of $P_{1}-P_{12}$

\section{Impactor displacement-time response}

The displacement-time histories of $\mathrm{P}_{1}$ are shown in Fig. 12, in which the displacement is represented by $\mathrm{D}$. A comparison shows that there was relatively good agreement between the test and simulation results; the maximum displacement error was only $2.1 \%$. Hence, the simulation model can well reflect the displacement variation of the impactor during the impact process.

In Fig. 13, the experiment and simulation results of the maximum impactor displacement of $\mathrm{P}_{1}-\mathrm{P}_{12}$ were consistent. The maximum displacement of $\mathrm{P}_{4}-\mathrm{P}_{6}$ was relatively large because $\mathrm{N}_{12}$ and $\mathrm{N}_{13}$ were chopped strand mats with low stiffness, and uniaxial cloth with high stiffness was set in the middle of the laminate. Therefore, the stiffness of the entire laminate was relatively low, and the corresponding maximum impactor displacement was relatively large. The maximum impactor displacements of $\mathrm{P}_{1}-\mathrm{P}_{3}$ and $\mathrm{P}_{7}-\mathrm{P}_{12}$ were slightly smaller. The reason for this was that $\mathrm{N}_{12}$ and $\mathrm{N}_{13}$ 
were uniaxial cloths. The stiffness of the whole laminate was relatively high, and the corresponding maximum impact force also increased accordingly. Under the same experimental conditions, the impactor displacement reflected the stiffness level of each laminate. Corresponding to different layup forms, the stiffness of the 12 laminates had the following relationship: $\mathrm{P}_{8}<\mathrm{P}_{12}<\mathrm{P}_{7}<\mathrm{P}_{2}<\mathrm{P}_{9}<\mathrm{P}_{10}<\mathrm{P}_{11}<\mathrm{P}_{1}<\mathrm{P}_{3}<\mathrm{P}_{6}<\mathrm{P}_{5}<\mathrm{P}_{4}$.

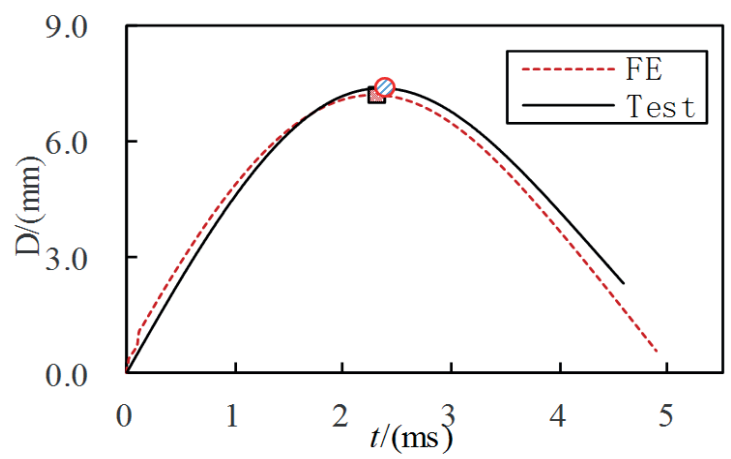

Fig. 12. Displacement-time histories of $P_{1}$

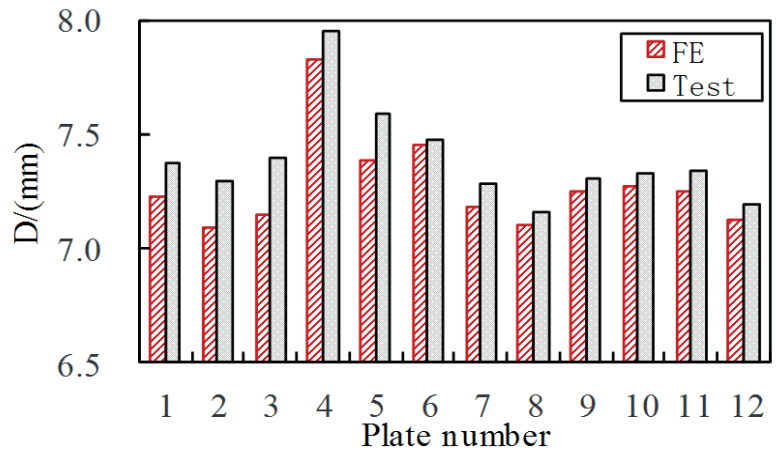

Fig. 13. Maximum impact displacements of $P_{1}-P_{12}$

\section{Rebound velocity/absorbed energy-time response}

The tests and simulations recorded the velocity change of the impactor during the impact process, which includes two parts: impact and rebound. During the impact process, the impactor velocity gradually decreased over time; in the process of rebound, the velocity of the impactor gradually increased due to the rebound force of the laminates until the impactor was out of contact with the laminates. Fig. 14 shows the velocity change of the impactor corresponding to $\mathrm{P}_{1}$ in the test and simulation, in which the velocity is represented by $v$. In this figure, the test and simulation results were basically consistent before the impactor displacement reached a maximum, but in the final stage of the impactor rebound, the simulation value gradually exceeded the experimental value. The error of the final rebound velocity was $11.7 \%$. The reason for this discrepancy was that the Tan stiffness degradation criterion was adopted in the simulation. The elements still had a certain stiffness after damage, which led to a higher rebound speed of the impactor. Fig. 15 shows the test and simulation results of the final rebound velocity of the impactor corresponding to $\mathrm{P}_{1}-\mathrm{P}_{12}$. Similar to $\mathrm{P}_{1}$, the simulated value of the rebound velocity was higher than the experimental value, and the impactor corresponding to $\mathrm{P}_{4}$ had the maximum rebound velocity.

In the whole impact process, the energy of the system, which was composed of a laminate and the impactor, was conserved. Therefore, the energy reduction of the impactor can be used to express the absorbed energy of the laminates. Fig. 16 shows the absorbed energy of $\mathrm{P}_{1}$ during the impact process, in which the energy is represented by the letter " $E$ ". Fig. 17 shows the final absorbed energy of $\mathrm{P}_{1}-\mathrm{P}_{12}$. This figure shows that in both the simulation and the experiment, $\mathrm{P}_{4}$ has the minimum absorbed energy. The hull plates need better impact resistance, such as a small damage area, less absorbed energy and so on. Thus, the carrying capacity of the hull structure can be maintained to a certain extent, and the water seepage efficiency can be reduced to ensure the safety of the ship. Therefore, its layup form is more in line with the requirements for composite ships, and can be used in the subsequent yacht design.

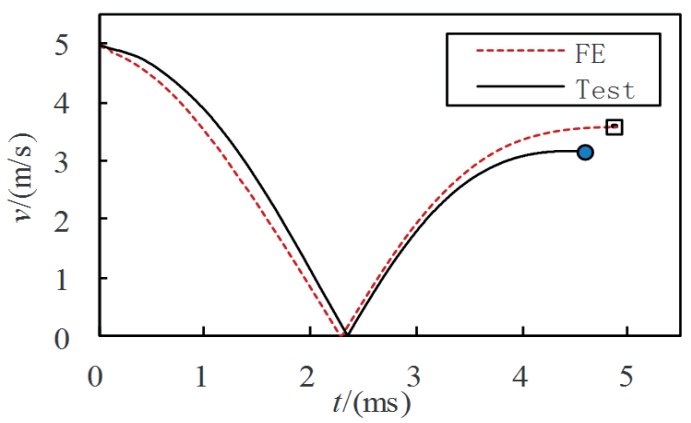

Fig. 14. Velocity-time histories of $P_{1}$

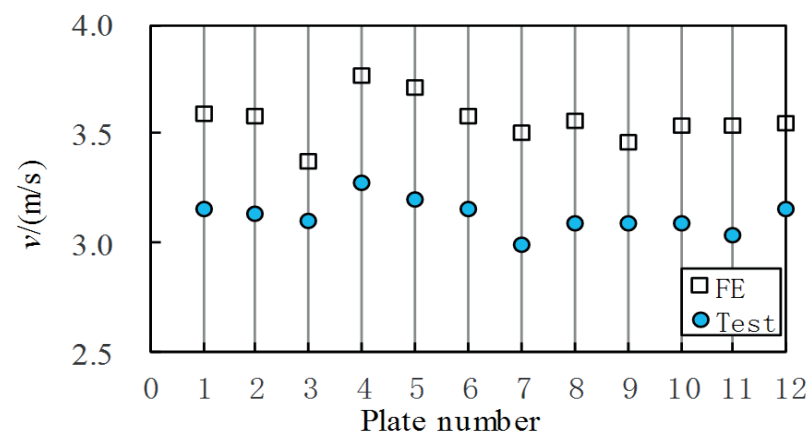

Fig. 15. Final rebound velocity of the impactor of $P_{1}-P_{12}$ 


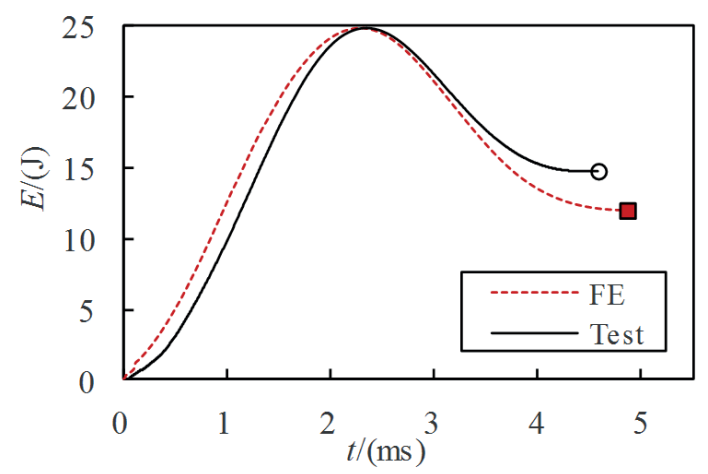

Fig. 16. Absorbed energy-time histories of $P_{1}$

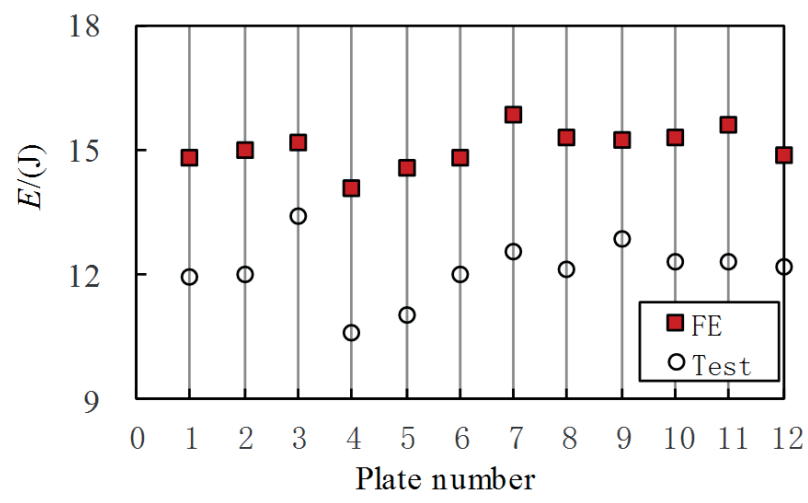

Fig. 17. Final absorbed energy of $P_{1}-P_{12}$

\section{CONCLUSION}

In this investigation, experimental and numerical investigations of composite plates under low-velocity impact were conducted. The analysed plates were made of GRP laminate with 12 different layup forms. A simulation model was established by writing a VUMAT subroutine. The experimental research was carried out with the use of the impact drop tower. And the numerical analyses were performed in the Abaqus program. Hashin's criterion and the cohesive zone model were implemented as the damage initiation criterion of intralaminar and interlaminar damage. The Tan criterion and B-K criterion were used to characterise the stiffness degradation of intralaminar and interlaminar damage elements. Based on the experimental and numerical studies performed, it has been concluded that:

1) The initial damage occurred at the impact side, and the material at the impact point was plastically deformed, resulting in a circular pit with a diameter of about $9 \mathrm{~mm}$. Due to the high contact force, the damage expanded rapidly to the interior of the laminate.

2) The low-velocity impact damage mainly occurs near the impact area. The damage areas for the same impact energy are larger for the back side than for the impact side. And the damage areas of each layer partially overlap.
3) The layup form had an important role in the damage on the impact side and back side of the composite laminates. Because of the same layup form of the first three layers, the pits diameter and damage areas of the impact side of the 12 plates are similar. And the damage on the back side of the specimens was closely related to the layup form of $\mathrm{N}_{12}$ and $\mathrm{N}_{13}$.

4) For the same impact energy, there is a corresponding layup form to minimise the damage area. There are 12 layup forms in this paper, and the damage area of $\mathrm{P}_{4}$ is the smallest.

5) In this paper, small cracks and fibre delaminations can be seen in the tested specimens under the low-velocity impact of 25J, but the energy is not enough to break the fibres on the back of the laminates.

6) Comparisons showed that the simulation and test results of the impact force, impactor displacement, rebound velocity and absorbed energy were in very good agreement. The validity of the numerical model is proved, and the numerical model can be successfully used for the initial prediction of the mechanical behaviour for composite laminates under low-velocity impact.

7) In this paper, the maximum impact force, absorbed energy and damage area of the plate $\mathrm{P}_{4}$ are the smallest among the 12 plates. In comparison, it has better impact resistance than others, so it is more in line with the requirements of composite ships.

\section{ACKNOWLEDGEMENTS}

This work was financed by the National Natural Science Foundation of China (Grant No. 51909103) and the Project of Fujian Provincial Department of Education of China (Grant No. JAT190336).

\section{REFERENCES}

1. Li X., Zhu Z., Li Y., Hu Z. (2020): Design and mechanical analysis of a composite t-type connection structure for marine structures. Polish Maritime Research, 2020, 27(2): $145-157$.

2. Tomasz F., Tomasz M. (2020):Validation process for computational model of full-scale segment for design of composite footbridge. Polish Maritime Research, 27(2): 158-167.

3. Li X., Zhu Z., Li Y., Hu Z., Dai L. (2020): A review on ultimate strength of composite-metal hybrid ships. Journal of Ship Mechanics, 24(05): 681-692.

4. Niksa-Rynkiewicz T., Landowski M., Szalewski P. (2020): Application of apriori algorithm in the lamination process in yacht production. Polish Maritime Research, 27(3): 59-70. 
5. Qiu A., Fu K., Zhao C., et al. (2013): Numerical understanding the impact behaviors of marine composite laminates. 1st International Conference on Advanced Composites for Marine Engineering. 2013.

6. Thorsson S. I., Waas A. M., Rassaian M. (2018): Numerical investigation of composite laminates subject to low-velocity edge-on impact and compression after impact. Composite Structures, 203.

7. Liao B., Zhou J., Lin Y., et al. (2019): Low-velocity impact behavior and damage characteristics of CFRP laminates. Chinese Journal of High Pressure Physics, 33(04): 105-113.

8. Oliveira Ferreira G. F., et al. (2019): Computational analyses of composite plates under low-velocity impact loading. Materials Today: Proceedings, 2019, 8.

9. Thorsson S. I., Waas A M., Rassaian M. (2018): Lowvelocity impact predictions of composite laminates using a continuum shell based modeling approach part A: Impact study. International Journal of Solids and Structures, 155: 185-200.

10. Panettieri E., Fanteria D., Montemurro M., Froustey C. (2016): Low-velocity impact tests on carbon/epoxy composite laminates: A benchmark study. Composites Part B, 107: 9-21.

11. Shi Y., Pinna C., Soutis C. (2014): Modelling impact damage in composite laminates: A simulation of intra- and interlaminar cracking. Composite Structures, 114.

12. Xu Y., Zuo H., Lu X., et al. (2019): Numerical analysis and tests for low-velocity impact damage evaluation of composite material. Journal of Vibration and Shock, 38(03): 149-155.

13. Gliszczynski A., et al. (2019): Barely visible impact damages of GFRP laminate profiles - An experimental study. Composites Part B: Engineering, 158: 10-17.

14. Gliszczynski A. (2018): Numerical and experimental investigations of the low velocity impact in GFRP plates. Composites Part B Engineering, 138: 181-193.

15. Moura M. D., Marques A. T. (2002): Prediction of low velocity impact damage in carbon-epoxy laminates. Composite: Part A, 33: 361-368.

16. Moura M. D., Goncalves J. P. (2004): Modelling the interaction between matrix cracking and delamination in carbon-epoxy laminates under low velocity impact. Composites Science and Technology, 64: 1021-1027.
17. Hou J. P., Petrinic N., Ruiz C., Hallett S. R. (2000): Prediction of impact damage in composite plates. Composite Science and Technology, 60: 273-281.

18. Luo R. K. (2000): The evaluation of impact damage in a composite plate with a hole[J]. Composite Science and Technology, 60: 49-58

19. Wen W., Xu Y., Cui H. (2007): Damage analysis of laminated composites under low velocity impact loading. Journal of Materials Engineering, 7: 6-11.

20. Zhu W. (2012): Research on residual strength and fatigue performance of composite laminates with low-velocity impact damage. Dissertation, Nanjing: Nanjing University of Aeronautics and Astronautics.

21. Zhu D., Zhang W., et al. (2014): Studies of several influence factors of low-velocity impact damaged characterization on composite laminates. Ship Science and Technology, 11: 57-65.

22. Dong H., An X., et al. (2015): Progress in research on low velocity impact properties of fibre reinforced polymer matrix composite. Journal of Materials Engineering, 43(5): 89-100.

23. Zu Z. (2020): Experimental investigation on repeated low velocity impact damage and residual compressive strength of honeycomb sandwich panel. Dissertation, Shandong: Shandong University of Technology.

24. Guden M., Yildirim U., Hall I. W. (2004): Effect of strain rate on the compression behavior of a woven glass fiber/ SC-15 composite. Polymer Testing, 23(6): 719-725.

25. Hosur M., Alexander J., Vaidya U., et al. (2004): Studies on the off-axis high strain rate compression loading composites. Composite Structures, 63(1): 75-85.

26. Hashin Z., Rotem A. (1973): A fatigue failure criterion for fiber reinforced materials. Journal of Composite Materials, 7(4): 448-464

27. Hashin Z. (1980): Failure criteria for unidirectional fiber composites. Journal of Applied Mechanics, 47(2): 329-334.

28. Ferreira R. T. L., Ashcroft I. A. (2020): Optimal orientation of fibre composites for strength based on Hashin's criteria optimality conditions. Structural and Multidisciplinary Optimization, 61: 2155-2176.

29. Chaht F. L., Mokhtari M., Benzaama H. (2019): Using a Hashin Criteria to predict the damage of composite notched plate under traction and torsion behavior. Fracture and Structural Integrity, 13(50): 331-341. 
30. Ha W. (2018): Study on failure modes and residual strength of composite laminates under low-velocity impact. Dissertation, Harbin: Harbin Institute of Technology.

31. Yang Y., Liu X., Wang Y. Q., et al. (2017): A progressive damage model for predicting damage evolution of laminated composites subjected to three-point bending. Composites Science and Technology, 151.

32. Sun X. (2018): Numerical simulation of gradual damage on bolt-bonded hole composite laminates. Dissertation, Harbin: Harbin Engineering University.

33. Shi J. (2015): The finite element analysis of the progressive damage of composite laminated plates based on ABAQUS. Dissertation, Shanxi: North University of China.

34. Abir M. R., Tay T. E., Ridha M., Lee H. P. (2017): Modelling damage growth in composites subjected to impact and compression after impact. Composite Structures, 168: 13-25.

35. Benzeggagh M. L., Kenane M. (1996): Measurement of mixed-mode delamination fracture toughness of unidirectional glass/epoxy composites with mixed-mode bending apparatus. Composites Science and Technology, 56(4): 439-449.

36. Chen Y., Yu Z., Wang H. (2012): Numerical modeling of scale effects on the responses of laminated composite plate under low velocity impact. Chinese Journal of Solid Mechanics, 33(6): 574-582.

37. Liu H. (2006): Numerical simulation of delamination damage in composite materials. Dissertation, Shanxi: Northwestern Polytechnical University.

38. Ji Z., Guan Z., Li Z. (2016): Damage resistance property of stiffened composite panels under low-velocity impact. Journal of Beijing University of Aeronautics and Astronautics, 42(04): 751-761.

\section{CONTACT WITH THE AUTHORS}

\author{
Xiaowen Li \\ e-mail: lixw2016@jmu.edu.cn
}

Jimei University, School of Marine Engineering, No.176, Shigu Road, 361021 Xiamen,

Fujian Provincial Key Laboratory for Naval Architecture and Ocean Engineering

\section{China}

\section{Zhaoyi Zhu}

e-mail: 1988zhuzhaoyi@163.com

Jimei University, School of Marine Engineering, No.176, Shigu Road, 361021 Xiamen,

Fujian Provincial Key Laboratory for Naval Architecture and Ocean Engineering

\section{China}

\section{Qinglin Chen}

e-mail: 199761000020@jmu.edu.cn

Jimei University, School of Marine Engineering, No.176, Shigu Road, 361021 Xiamen,

Fujian Provincial Key Laboratory for Naval Architecture and Ocean Engineering

\section{China}

\section{Yingqiang Cai \\ e-mail:200661000102@jmu.edu.cn}

Jimei University, School of Marine Engineering, No.176, Shigu Road, 361021 Xiamen,

Fujian Provincial Key Laboratory for Naval Architecture and Ocean Engineering

\section{China}

\section{Yunfeng Xiong}

e-mail:200561000043@jmu.edu.cn

Jimei University, School of Marine Engineering, No.176, Shigu Road, 361021 Xiamen,

Fujian Provincial Key Laboratory for Naval Architecture and Ocean Engineering

China 